\title{
The development of preparation, conflict monitoring and inhibition from early childhood to young adulthood: a Go/Nogo ERP study
}

Citation for published version (APA):

Jonkman, L. M. (2006). The development of preparation, conflict monitoring and inhibition from early childhood to young adulthood: a Go/Nogo ERP study. Brain Research, 1097(1), 181-93.

https://doi.org/10.1016/j.brainres.2006.04.064

Document status and date:

Published: 01/01/2006

DOI:

10.1016/j.brainres.2006.04.064

Document Version:

Publisher's PDF, also known as Version of record

Document license:

Taverne

Please check the document version of this publication:

- A submitted manuscript is the version of the article upon submission and before peer-review. There can be important differences between the submitted version and the official published version of record.

People interested in the research are advised to contact the author for the final version of the publication, or visit the DOI to the publisher's website.

- The final author version and the galley proof are versions of the publication after peer review.

- The final published version features the final layout of the paper including the volume, issue and page numbers.

Link to publication

\footnotetext{
General rights rights.

- You may freely distribute the URL identifying the publication in the public portal. please follow below link for the End User Agreement:

www.umlib.nl/taverne-license

Take down policy

If you believe that this document breaches copyright please contact us at:

repository@maastrichtuniversity.nl

providing details and we will investigate your claim.
}

Copyright and moral rights for the publications made accessible in the public portal are retained by the authors and/or other copyright owners and it is a condition of accessing publications that users recognise and abide by the legal requirements associated with these

- Users may download and print one copy of any publication from the public portal for the purpose of private study or research.

- You may not further distribute the material or use it for any profit-making activity or commercial gain

If the publication is distributed under the terms of Article 25fa of the Dutch Copyright Act, indicated by the "Taverne" license above, 


\title{
Research Report
}

\section{The development of preparation, conflict monitoring and inhibition from early childhood to young adulthood; a Go/Nogo ERP study}

\author{
Lisa M. Jonkman* \\ Faculty of Psychology, Dept. of Neurocognition, Maastricht University, P.O. Box 616, 6200 MD Maastricht, The Netherlands
}

\section{A R T I C L E I N F O}

Article history:

Accepted 17 April 2006

Available online 26 May 2006

Keywords:

Child development

Response inhibition

Event-related potential

Nogo-N2, Nogo-P3

$\mathrm{CNV}$

\begin{abstract}
A B S T R A C T
The present developmental study aimed to trace changes in response expectation, preparation, conflict monitoring and subsequent response inhibition from 6 years of age to adulthood. In two groups of children (6-7 and 9-10 years old) and young adults (1923 years old), behavior and event-related brain activity (ERP) in a CPT-AX task was measured. Hits, false alarms, inattention and impulsivity scores and ERP measures of conflict monitoring and inhibition (Nogo-N2 and P3), cue-orientation and prestimulus target expectation (cue-P2 and P3) and response preparation (Contingent Negative Variation; $\mathrm{CNV}$ ) were collected. Behavioral measures indicated that attention processes developed most strongly before age 10, whereas impulsive behavior only started to diminish after the age of 10. Nogo-N2 effects were largest and more widely distributed across fronto-parietal electrodes in 6-7-year olds and decreased linearly with age. Nogo-P3 effects showed an opposite pattern by being absent in the youngest children, starting to develop at age 9-10 and reaching maturity in young adulthood. These developmental behavioral and ERP results are supportive of links between Nogo-N2 and conflict monitoring and Nogo-P3 and response inhibition and suggest that both are liable to different developmental progress. Furthermore, enhanced cue-P3 activity in both 6-7 and 9-10-year olds was argued to reflect a higher level of Go-stimulus expectation, that might cause them to experience more conflict on subsequent Nogo-trials, when the 'not-expected' stimulus appears. On the other hand, young children's reduced preparatory CNV activity was interpreted as a sign of reduced response priming caused by yet immature fronto-parietal networks involved in motor regulation.
\end{abstract}

(c) 2006 Elsevier B.V. All rights reserved.

\section{Introduction}

Our daily environment is filled with information from different sources. In order to control behavior and stick to certain task goals instead of others in such a rich environment, adequate employment of executive control is necessary. In the past de- cennia, it has become clear that at the cognitive level different executive control processes can be distinguished that are in adults localized in different parts of anterior cingulate cortex (for review, see Ridderinkhof et al., 2004). Processes like selective attention, stimulus or response expectation and preparation, conflict monitoring and response inhibition, e.g. the ability to

\footnotetext{
* Fax: +31 433884125 .

E-mail address: L.Jonkman@psychology.unimaas.nl.
} 
actively suppress or interrupt an activated response, are all very important to establish efficient and goal directed behavior.

Studies that employ cognitive tasks that require suppression of information or responses that are in conflict with the primary task goals show that whereas adults appear to be quite efficient in the employment of different forms of executive control, children perform considerably worse on such tasks. From the abovementioned executive control processes, response inhibition has by far received the most attention in developmental studies. The ability to inhibit shows a progressive development from early childhood to adulthood (Williams et al., 1999). Furthermore, behavioral and fMRI studies indicate that executive control processes such response inhibition, undergo profound development between late childhood and adolescence and this is ascribed to the late structural development of the frontal cortex (Kanemura et al., 2003; Sowell et al., 1999; Luna and Sweeney, 2004). Although other executive control processes like response preparation and conflict monitoring have also been localized in specific areas of prefrontal cortex in adults, not much is known about the neurocognitive development of these specific processes in children and it is the main aim of the present study to increase such insights.

An experimental task that enables the study of different executive control processes is the so-called cued-Go/Nogo task. In such a task, the primary assignment is to respond to Go stimuli (e.g. letter X) and to inhibit responses on Nogo trials (e.g. letter $\mathrm{O}$ ). The strength of the required inhibition can be manipulated by enhancing the strength of response priming or preparation. This can be established by either enhancing Go probability, thereby establishing a stronger overall urge to respond, or by presenting warning signals (e.g. letter A) to which a prepotent response is prepared that has to be respectively executed or inhibited on subsequent Go or Nogo trials. In such paradigms, executive control processes that cannot be directly derived from behavior can be studied by measuring event-related brain potentials (ERPs). Examples of such processes are the level of preparation for an upcoming stimulus at a certain time-point following a warning stimulus or the level of experienced conflict and the strength of the inhibition required when the expectancy of a Go stimulus is violated. By comparing ERPs evoked by warning stimuli that predict the occurrence of the Go stimulus with ERPs evoked by task-irrelevant stimuli without predictive value (NoCue ERPs), one can study the level of Go-stimulus expectation and response preparation. The comparison of Go and Nogo ERPs gives information about the level of conflict and response inhibition that is evoked by Nogo stimuli. These processes of stimulus expectation, response preparation, conflict monitoring and response inhibition have all been linked to specific ERP components in Go/Nogo tasks in earlier studies involving adult subjects and will be discussed in the following paragraph.

The ERP response evoked by warning stimuli is marked by an early positivity with a maximum at fronto-central sites (P2), followed by a second positivity with a centro-parietal maximum (P3a) and a broadly distributed Contingent Negative Variation (CNV) across frontal, central and parietal electrodes. The cue-P2 and P3 can respectively be interpreted as signs of cue-detection and further cue-evaluation (evaluation of the relevance of the cue in predicting the upcoming event; Banaschewski et al., 2003; Bekker et al., 2004; Van Leeuwen et al., 1998), whereas the late part of the CNV has been associated with response preparation processes (McCallum, 1988; Rohrbaugh and Gaillard, 1983), the larger the CNV activity, the stronger the response preparation.

In comparison to Go-ERPs, Nogo stimuli, or other stimuli requiring the inhibition of a prepared response, evoke ERPs consisting of an enhanced negativity (Nogo-N2) that is followed in time by a positivity (Nogo-P3) in an interval from 200-500 ms poststimulus at fronto-central electrodes (Bruin and Wijers, 2002; Bruin et al., 2001; Ramautar et al., 2004; Van 't Ent and Apkarian, 1999). Recently, the functional significance of the Nogo-N2 component has been debated. Although the Nogo-N2 has traditionally been associated with the inhibition of motor responses (Jodo and Kayama, 1992; Kok, 1986), recent evidence convincingly relates the Nogo-N2 to the process of conflict monitoring (Donkers and Van Boxtel, 2004; Nieuwenhuis et al., 2003). According to conflict monitoring theory, the process of conflict monitoring is activated whenever there is conflict between the prepotent response and the currently required response. But in cuedGo/Nogo tasks or in tasks in which there is high Go probability, conflict might also arise in the Nogo condition because Go-expectancy is violated (see Bekker et al., 2004). The source of the N2 component in conflict or Go-Nogo tasks has been repeatedly localized in the Anterior Cingulate Cortex (ACC) (Bekker et al., 2005; Nieuwenhuis et al., 2003; Van Veen and Carter, 2002a,b) and activation of caudal parts of ACC and pre-SMA regions have in turn been linked to conflict monitoring in fMRI studies (for review, see Botvinick et al., 2004; Fassbender et al., 2004).

In adult subjects, the Nogo-P3 component, that follows the Nogo-N2 in time, has consistently been reported to occur in Go/Nogo tasks with or without warning stimuli (Bekker et al., 2004; Bruin and Wijers, 2002; Bruin et al., 2001; Donkers and Van Boxtel, 2004; Fallgatter et al., 1997). The generating source of the Nogo-P3 has been localized in left orbitofrontal cortex (Bokura et al., 2001) and the fronto-central distribution of the Nogo-P3 disscociates this component from the Go-P3 that has a parietal dominance. As opposed to the Nogo-N2, evidence relating the Nogo-P3 to response inhibition is accumulating (Bruin et al., 2001; Bekker et al., 2004; Donkers and Van Boxtel, 2004). Bruin et al. (2001) showed that the Nogo-P3 amplitude was enhanced when responses were more strongly primed, thus requiring stronger inhibition. In Bekker et al. (2004), the level of response preparation (CNV amplitude) in the cuetarget interval appeared to be associated with Nogo-P3 amplitude.

ERP studies investigating the development of abovementioned executive control processes and their ERP correlates are scarce. Such studies are, however, important for several reasons. First, knowledge about the normal development of executive control processes and their neurobiological basis is crucial for predicting sensitive periods in development, which is important for the prevention of deviant behavior such as in Attention-Deficit Hyperactivity Disorder (ADHD). Second, developmental neurocognitive studies might contribute to theory development, by testing the validity of conclusions concerning functional significance of ERP components, such 
as links between conflict-monitoring and Nogo-N2 and response inhibition and nogo-P3, that are in most cases purely based upon adult research. In an earlier study from our lab (Jonkman et al., 2003), the performance and ERP activity of 910-year-old children and adults performing a CPT-AX task were compared. Children reacted more impulsively and less attentively than adults, showed similar frontal Nogo-N2 effects, but reduced, or absent frontal Nogo-P3 effects. The absence of a Nogo-P3 at this age was interpreted as a sign of immature response inhibition. Such late development of frontal Nogo-P3 activity was also reported in a recent developmental ERP study by Okazaki et al. (2004), using a similar task and in an auditory Go/Nogo task by Johnstone et al. (2005). Besides our previous study, there are only two developmental studies reporting on the Nogo-N2. Ciesielski et al. (2004) reported larger Nogo-N2 effects in children than in adults, but at the parietal lead. In Jonkman et al. (2003), maximal NogoN2 effects were reported above frontal cortex and did not differ between children and adults. These differences might be explained by differences in age; in Ciesielski et al., the childgroup was composed of children ranging from 6-12 years of age, whereas in Jonkman et al., a narrow age range of 910 years was employed. In contrast to the abovementioned studies, Davis et al. (2003) did not find significant Go/Nogo-N2 effects in 6-year-old children or adults performing a Go/Nogo task, but this is probably due to the different task design used in this study, in which Go and Nogo trials were not randomly intermixed.

Whereas the previous review shows that developmental ERP studies focusing on Nogo-N2 and P3 are scarce, as far as we know studies reporting on developmental differences in early ERP responses to warning stimuli (cue-P2 and P3) that precede Go/Nogo stimuli are lacking. As yet, only a few studies have investigated the normal development of response preparation by measurement of CNV (Jonkman et al., 2003; Segalowitz and Davies, 2004; Segalowitz et al., 1992), but these studies did not report on cue-orientation (P2) or stimulus expectation (P3). In two clinical studies, significantly reduced field power of cue-P2/P3 has been reported in children with Hyperkinetic Disorder (HD) or Attention-Deficit Disorder (ADD). This reduced P2/P3 activity was interpreted as either impaired orienting (Van Leeuwen et al., 1998) or suboptimal energetical state regulation (Banaschewski et al., 2003) in the cue-target interval, causing these children to be less prepared for the upcoming task. Accordingly, Banaschewski et al. also reported reduced CNV activity in these children. Knowledge about the normal developmental course of such executive control processes is missing but is crucial for detecting the sensitive periods for developing such deficits.

The main aim of the present study is to get a more complete picture of the development of different executive control processes evoked by Cues and by Nogo stimuli by elaborating the design in several ways in comparison to previous studies. First, the 9-10-year-old and adult groups from Jonkman et al. (2003) are enlarged and a group of younger children, 6-7 years old, was included. Second, besides the study of Go/Nogo ERP differences (reflecting conflict monitoring and response inhibition), cue-elicited ERPs were analyzed and compared to NoCue ERPs, to study both early cue-processing (cue-orientation and Go-expectancy; P2 and P3) and response preparation (CNV). Third, the topography of Nogo-N2 and P3 effects in both children groups and adults was studied across 30 leads to be able to conclude whether there are indications for developmental differences in the location of sources underlying the executive processes of conflict monitoring and inhibition. Nogo-N2 topography analyses in the present study were performed by correcting for possibly overlapping, surrounding ERP activity, according to Bekker et al. (2005). Specific expectations are that when Nogo-N2 and Nogo-P3 have different functional significance they will show different developmental patterns. Jonkman et al. (2003) reported increased impulsive behavior and reduced or absent Nogo-P3 effects in 9-10-year-old children and interpreted this as a sign of reduced response inhibition capacity. If this conclusion is correct, Nogo-P3 effects should be absent in 6-7year-old children in the present study. Our previous study showed similar Nogo-N2 effects in 9-10 year old children and adults above frontal leads whereas Ciesielski et al. (2004) did report differences, but only across parietal leads. The present topographical analyses and inclusion of a younger age group might lead to a further explanation of these findings and might elaborate on adult studies reporting links between the Nogo-N2 and the process of conflict monitoring (Bekker et al., 2004) in a similar task. Significant developmental differences in conflict monitoring behavior have been reported to occur between early and late childhood (Ridderinkhof et al., 1997; Rueda et al., 2004a), and related ERP activity is expected to follow the same developmental pattern. In this context, Rueda et al. (2004b) reported conflict-related negativity above frontal cortex to occur already in 4-year-old children. Expectations regarding developmental differences in Cueelicited ERPs are less clear due to the lack of studies in this field; cue stimuli might induce stronger orientation (P2) and expectancy (P3) responses in children, but this might also be the other way around. Young children are, however, expected to be less adequate in response preparation (reduced CNV amplitude) at least compared to adults based on Jonkman et al. (2003).

\section{Results}

\subsection{Behavioral results}

The mean percentages and SDs of hits (correct Go responses), total amount of false alarms, Impulsivity and Inattention scores, mean RTs to Go stimuli (Go-RT) and Go-RT variability (differences in standard deviations of RT) in the three groups are presented in Table 1 . Significant age effects appeared for percentage of hits $(F(2,47)=10.01, P<0.0001)$, Go$\operatorname{RT}(F(2,47)=5.42, P<0.005)$, Go-RT variability $(F(2,47)=23.47$, $P<0.0001)$, percentage of false alarms to Nogo stimuli $(F(2,47)=3,52, P<0.05)$, Impulsivity scores $(F(2,47)=3.44$, $P<0.05)$ and the Inattention score $(F(2,47)=9.35, P<0.0001)$. Further differences between the three age groups were tested by performing independent $t$ tests. It appeared that younger children differed from older children in the percentage of hits $(t=-2.38, P<0.05)$, Go-RT $(t=2.16, P<0.05)$, Go-RT variability $(t=2.20, P<0.05)$ and the Inattention score $(t=2.37, P<0.05)$; younger children were more inattentive as evidenced by a 
Table 1 - Group means (standard deviations between brackets) of the behavioral parameters in the CPT-AX task, divided into attention and impulsivity measures

\begin{tabular}{|c|c|c|c|c|c|c|}
\hline & \multicolumn{4}{|c|}{ Attention measures } & \multicolumn{2}{|c|}{ Impulsivity measures } \\
\hline & Hits (\%) & Go-RT (ms) & Variability Go-RT(ms) & Inattention score (\%) & Impulsivity score (\%) & A-not-X FA (\%) \\
\hline $6-7$ years & $88(11)^{* * *}$ & $560(126)^{* *}$ & $150(35)^{* * *}$ & $6.1(5.5)^{* * *}$ & $0.6(0.8)^{*}$ & $1.8(2.5)^{*}$ \\
\hline 9-10 years & $96(6)$ & 470 (101) & $126(28)$ & $2.4(3.3)$ & $0.6(1.0)$ & $1.8(2.7)$ \\
\hline 20-22 years & $99(2)$ & $415(79)$ & $126(28)$ & $0.6(1.1)$ & $0.04(0.2)$ & $0.1(0.5)$ \\
\hline $\begin{array}{l}\text { A-not-X FA } \\
{ }^{*} \text { Group ef } \\
{ }^{* *} \text { Group ef } \\
{ }^{* * *} \text { Group ef }\end{array}$ & $\begin{array}{l}\text { total amou } \\
\text { ct significa } \\
\text { ct significa } \\
\text { ct significa }\end{array}$ & $\begin{array}{l}\text { t of false alarm } \\
\text { t at } P<0.05 \text {. } \\
\text { t at } P<0.005 \text {. } \\
\text { t at } P<0.0001 \text {. }\end{array}$ & o Nogo stimuli; RT = re & & & \\
\hline
\end{tabular}

higher Inattention score, a lower percentage of detected targets and a slower and more variable response pattern. No differences between 6-7 years olds and 9-10 years olds were reported regarding the percentage of Nogo false alarms $(P=0.98)$ and the Impulsivity score $(P=0.90)$. Both groups of children differed from young adults in \% hits, Go-RT variability, $\%$ false alarms, Impulsivity and Inattention scores (see Table 1). A difference in hit-reaction time was only found between the younger children and adults.

IQ correlated significantly with all behaviorally dependent measures ( $r$ ranging from -0.26 to $0.33, P$ between 0.02 and 0.05), except Impulsivity scores and Nogo false alarm, but all abovementioned main Group effects remained significant after performing covariance analyses (Main Group effects: Inattention scores, Hits and Go-RT: P < 0.005; Go-RT variability $P<0.0001)$.

\subsection{ERP results}

Grand average ERP-waves in the three groups and in Go and Nogo conditions at $\mathrm{Fz}, \mathrm{FCz}, \mathrm{Cz}$ and $\mathrm{Pz}$ are depicted in Fig. 1. Mean Nogo/Go N2 and P3 area amplitudes and SDs (at Fz, FCz) in predetermined time windows for the separate groups are given in Table 2.

\subsubsection{Go-Nogo analyses}

Nogo-N2 activity was maximal from $320-360 \mathrm{~ms}$ in 6-7-year olds, 280-320 ms in 9-10-year olds and 240-260 ms in adults (in all groups, Go/Nogo effects in these windows were significant at $\mathrm{P}<0.01$ level). The largest Nogo-positivity (Nogo-P3) following the N2 occurred from $440-480 \mathrm{~ms}$ in the youngest children, from 380-420 ms in older children and 360-400 ms in adults; Go/Nogo-P3 differences (Nogo > Go) were significant at $\mathrm{P}<0.01$ level at both $\mathrm{Fz}$ and $\mathrm{FCz}$ in older children and adults, but not in the 6-7 year olds, who showed no significant Nogo-P3.

2.2.1.1. Nogo-N2 effects. Mean amplitudes in the abovementioned time windows were entered in repeated measures analyses of variance to test for Leads (Fz and FCz) $\times$ StimulusType (Go/Nogo) × Group (6-7 years, 9-10 years, adults) interactions. For the Nogo-N2, this resulted in a significant three-way interaction $(F(2,47)=3.9, P<0.05)$. Further testing at the separate leads revealed significant StimulusType $\times$ Group interactions at both Fz and FCz $(P<0.0001)$. Group contrasts indicated that at both $\mathrm{Fz}$ and $\mathrm{FCz}$, the 6-7 year old children had significantly increased Nogo-N2 effects compared to both 9-
10 -year olds and adults $(P<0.0001)$, whereas 9-10 year olds and adults had similar Nogo-N2 effects ( $P$ between 0.28 and 0.31 ); see Table 2 for means in all groups. An extra post hoc test was performed on the N2-difference scores (Nogo-Go) to test the linearity of Nogo-N2 effects across age. The linear contrast was highly significant at both Fz and FCz $(F(1,47)=20.3$ and 30.0, respectively, $P<0.00001)$ whereas the quadratic contrast was not significant at $\mathrm{Fz}(P=0.14)$ and much smaller than the linear contrast at FCz $(P=0.04)$.

2.2.1.2. Nogo-P3 effects. The Nogo-P3 analyses also yielded a significant Leads $(\mathrm{Fz}$ and $\mathrm{FCz}) \times$ StimulusType $(\mathrm{Go} / \mathrm{Nogo}) \times$ Group interaction $(F(2,47)=7.1, P<0.01)$. Further testing revealed significant StimulusType $\times$ Group interactions at $\mathrm{Fz}$ $(F(2,47)=6.0, P<0.01)$ and FCz $(F(2,47)=3.3, P<0.05)$. Further testing between groups revealed differences between $\mathrm{Fz}$ and FCz locations; at FCz, both 6-7 and 9-10-year olds had smaller NogoP3 effects than adults $(P<0.05$ and $P<0.01$, respectively), at $\mathrm{Fz}$ this was only the case for the youngest children $(P<0.01)$ (see Fig. 1). No significant differences in Nogo-P3 were found between 6-7 and 9-10-year olds (both leads $P=0.43$ ). A polynomial contrast analysis was also performed on P3 Nogo-Go difference scores and indicated that the fronto-central NogoP3 increased linearly across age $(F(1,47)=5.9, P<0.05$; at both Fz and FCz). The quadratic contrasts were not significant $(P$ between 0.30 and 0.70 ).

\subsubsection{Cue-NoCue analyses}

The grand average Cue-NoCue difference waves from children and adults at $\mathrm{Fz}, \mathrm{Cz}, \mathrm{Pz}$ and $\mathrm{Oz}$ are presented in Fig. 2. The mean amplitude and SDs of the P2, P3 and CNV in Cue and NoCue conditions in the different time windows and groups are presented in Table 3.

2.2.2.1. Cue-P2 effects. Cue-P2 enhancement was present in all groups and was statistically largest $(P<0.0001)$ between 240 and $260 \mathrm{~ms}$ in both children groups and between 220 and $260 \mathrm{~ms}$ in adults. No significant CueType $\times$ Group interaction was found.

2.2.2.2. Cue-P3 effects. The $\mathrm{P} 3$ window analysis showed that parietal P3 effects (Cue $>$ NoCue) were largest between 350 and $800 \mathrm{~ms}$ in 6-7-year olds, between 350 and $700 \mathrm{~ms}$ in 9-10-year olds and between 300 and $600 \mathrm{~ms}$ in adults (all Ps $<0.0001$ ). Repeated measures analyses of variance revealed a significant Leads $\times$ CueType $\times$ Group interaction $(F(92,4)=3.9, P<0.01)$ which was further tested at the three separate leads $(\mathrm{Cz}, \mathrm{Pz}$, 


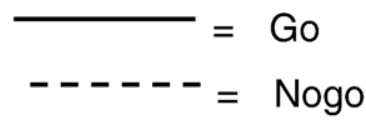

6,7 years

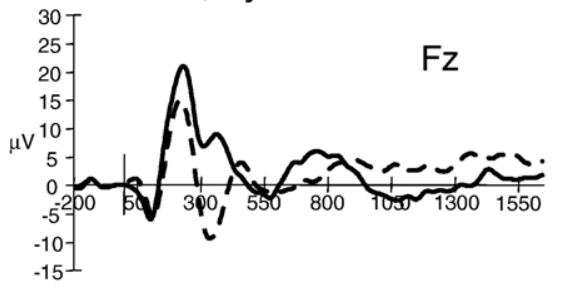

$\mathrm{ms}$

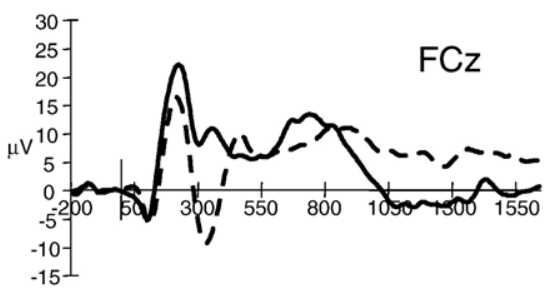

$\mathrm{ms}$
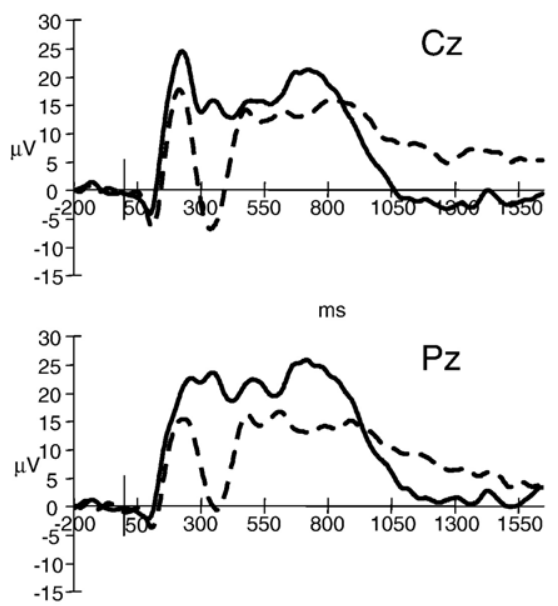

ms
9,10 years

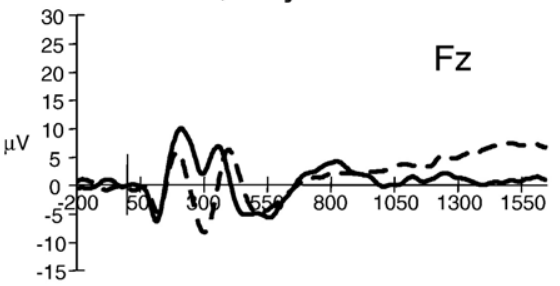

ms

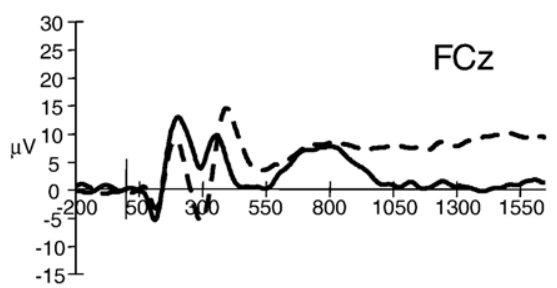

ms

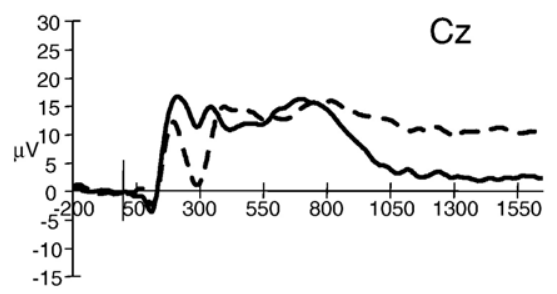

ms

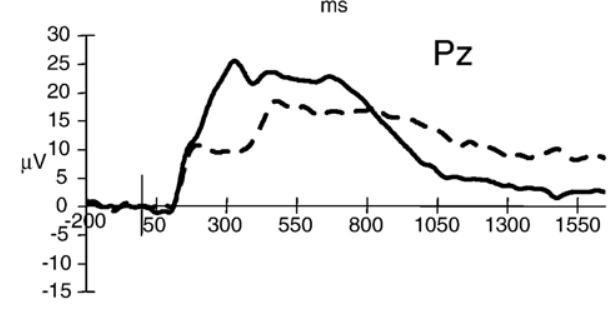

$\mathrm{ms}$

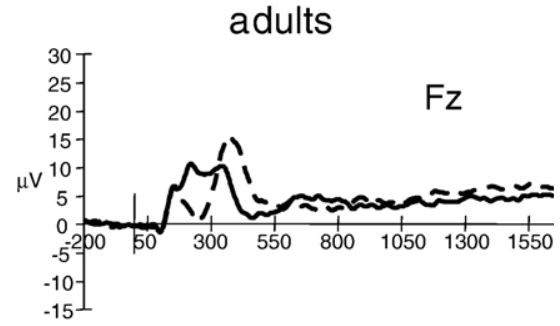

$\mathrm{ms}$

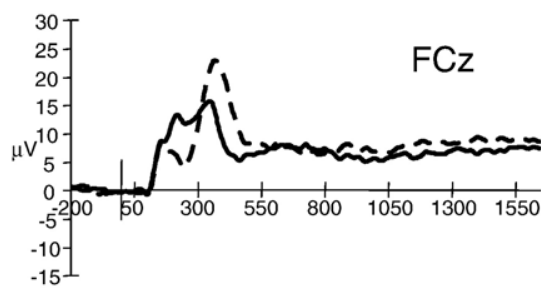

$\mathrm{ms}$

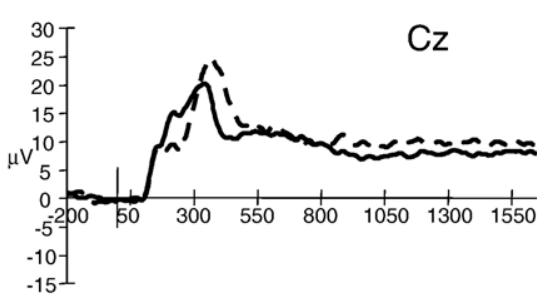

$\mathrm{ms}$

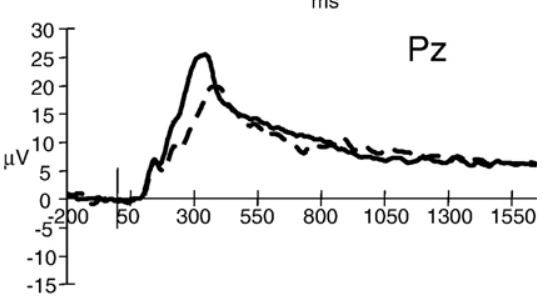

$\mathrm{ms}$

Fig. 1 - Grand average ERPs of both groups of children and adults in Go and Nogo conditions at four midline leads (Fz, FCz, $\mathrm{Cz}$ and $\mathrm{Pz}$ ).

Oz). A significant CueType $\times$ Group interaction was only present for the occipital electrode $(F(2,47)=4.8, P<0.05)$. Further testing indicated that at $\mathrm{Oz}$, the CueType effect was significantly larger in 6-7 and 9-10 year old children than in adults (CueType $\times$ Group: $P<0.01$ and $P<0.05$, respectively), young and old children did not differ from each other in cue P3 amplitude.

2.2.2.3. Cue CNV effects. The CNV analysis revealed a significant Group $\times$ CueType interaction $(F(2,47)=3.2, P<0.01)$, but no interaction with Leads. Therefore, Cue and NoCue amplitudes were averaged over the four midline leads, before further Group contrasts were computed. Post hoc tests yielded significantly smaller CNV amplitudes in 6-7 year old children when compared to 9-10-year olds $(P<0.05)$ and adults $(P<0.005)$ across the four midline leads, whereas there were no differences between older children and adults (see Fig. 2 and Table 3). The linear Group contrast for the Cue-NoCue
CNV difference score averaged over leads was also significant $(F(1,47)=8.7, P<0.006)$, whereas the quadratic contrast was not.

\subsection{Topographic analyses}

2.3.1. Age differences in the scalp distribution of Nogo-N2 and P3

Voltage maps of Nogo-N2 and P3 activity across 30 electrodes for children and adults are depicted in Fig. 3.

2.3.1.1. Nogo-N2. Before topographic analyses were performed, the Nogo-N2 distribution was corrected for surrounding P2 and P3 activity (see Bekker et al., 2005). The explorative analysis showed significant Group effects at all leads at $\mathrm{P}<0.00001$ level, except at Oz, O2, T5 and T6. At TP8, the group effect was significant at $\mathrm{P}<0.05$ and at $\mathrm{O} 1$ there was a trend for a Group effect $(P<0.08)$. The multivariate analysis 
Table 2 - Mean area amplitudes in $\mu \mathrm{V}$ (standard deviations between brackets) in the time windows in

which Nogo-N2 and Nogo-P3 amplitudes were maximal in the different groups (windows indicated in first column) in Go and Nogo conditions at Fz and FCz

\begin{tabular}{|c|c|c|c|c|}
\hline & \multicolumn{2}{|c|}{ Go } & \multicolumn{2}{|c|}{ Nogo } \\
\hline & $\mathrm{Fz}$ & $\mathrm{FCz}$ & $\mathrm{Fz}$ & $\mathrm{FCz}$ \\
\hline \multicolumn{5}{|l|}{ N2 } \\
\hline $\begin{array}{l}6-7 \text { years } \\
\quad(320-360 \mathrm{~ms})\end{array}$ & $8.2(8.0)$ & $10.3(9.8)$ & $-9.0(8.0)$ & $-9.0(10.3)$ \\
\hline $\begin{array}{l}\text { 9-10 years } \\
\quad(280-320 \mathrm{~ms})\end{array}$ & $2.6(7.8)$ & $4.8(9.0)$ & $-8.0(6.7)$ & $-4.6(8.0)$ \\
\hline $\begin{array}{l}\text { Adults } \\
\qquad(240-260 \mathrm{~ms})\end{array}$ & $9.3(3.9)$ & $11.9(5.5)$ & $0.7(5.4)$ & $4.3(6.2)$ \\
\hline \multicolumn{5}{|l|}{ P3 } \\
\hline $\begin{array}{l}6-7 \text { years } \\
\quad(440-480 \mathrm{~ms})\end{array}$ & $1.3(9.6)$ & $6.0(11.4)$ & $3.6(8.7)$ & $9.6(10.3)$ \\
\hline $\begin{array}{l}9-10 \text { years } \\
\quad(380-420 \mathrm{~ms})\end{array}$ & $1.2(8.7)$ & $4.5(9.6)$ & $5.6(8.8)$ & 13.9 (11.6) \\
\hline $\begin{array}{l}\text { Adults } \\
\qquad(360-400 \mathrm{~ms})\end{array}$ & $6.7(4.5)$ & $11.5(5.4)$ & $15.0(6.4)$ & $21.9(7.4)$ \\
\hline
\end{tabular}

yielded a Location (4) $\times$ Hemisphere (3) $\times$ Group (3) interaction $(F(12,86)=4.8, P<0.00001)$. Next, frontal and fronto-central and centro-parietal and parietal amplitudes were averaged to obtain one frontal and parietal value. Further tests at left, right and midline positions showed significant Location (frontal vs. parietal) $\times$ Group (3) interactions at left and right hemispheres $(P<0.05)$ and midline $(P<0.00001)$ positions. Comparisons between groups showed that the Nogo-N2 distribution across fronto-parietal leads did not differ significantly between younger children and adults. Although NogoN2 amplitudes were higher at all locations in 6-7 year-olds, the frontal-parietal difference was similar in both groups, NogoN2 amplitudes being largest at fronto-central electrodes. At midline locations, the older children's distribution did differ from that of both younger children and adults $(P<0.00001)$, in that they showed larger fronto-parietal Nogo-N2 differences, due to smaller Nogo-N2 activity at $\mathrm{Pz}$ caused by the presence of a positive field only in this group (see Fig. 3). Above left and right hemispheres, the distribution of 9-10-year olds only differed from that of adults (both effects $P<0.01$ ); 9-10-year olds had larger frontal-parietal differences due to stronger frontal, relative to parietal Nogo-N2 activity, probably also caused by the presence of the parietal positive field.

An extra analysis was performed for TP7 and TP8 leads since bilateral posterior activity is clearly visible in the NogoN2 maps of children. This analyses confirmed that 6-7 yearolds had larger bilateral positivity at temporal-parietal leads than older children (TP7 $P<0.00001$ and TP8 $P<0.05$ ) and adults (both leads $P<0.00001$ ). Differences between 9-10-year olds and adults were not significant.

2.3.1.2. Nogo-P3. The explorative analysis including all 30 leads showed no Group effects at occipital (O1, Oz, O2) and

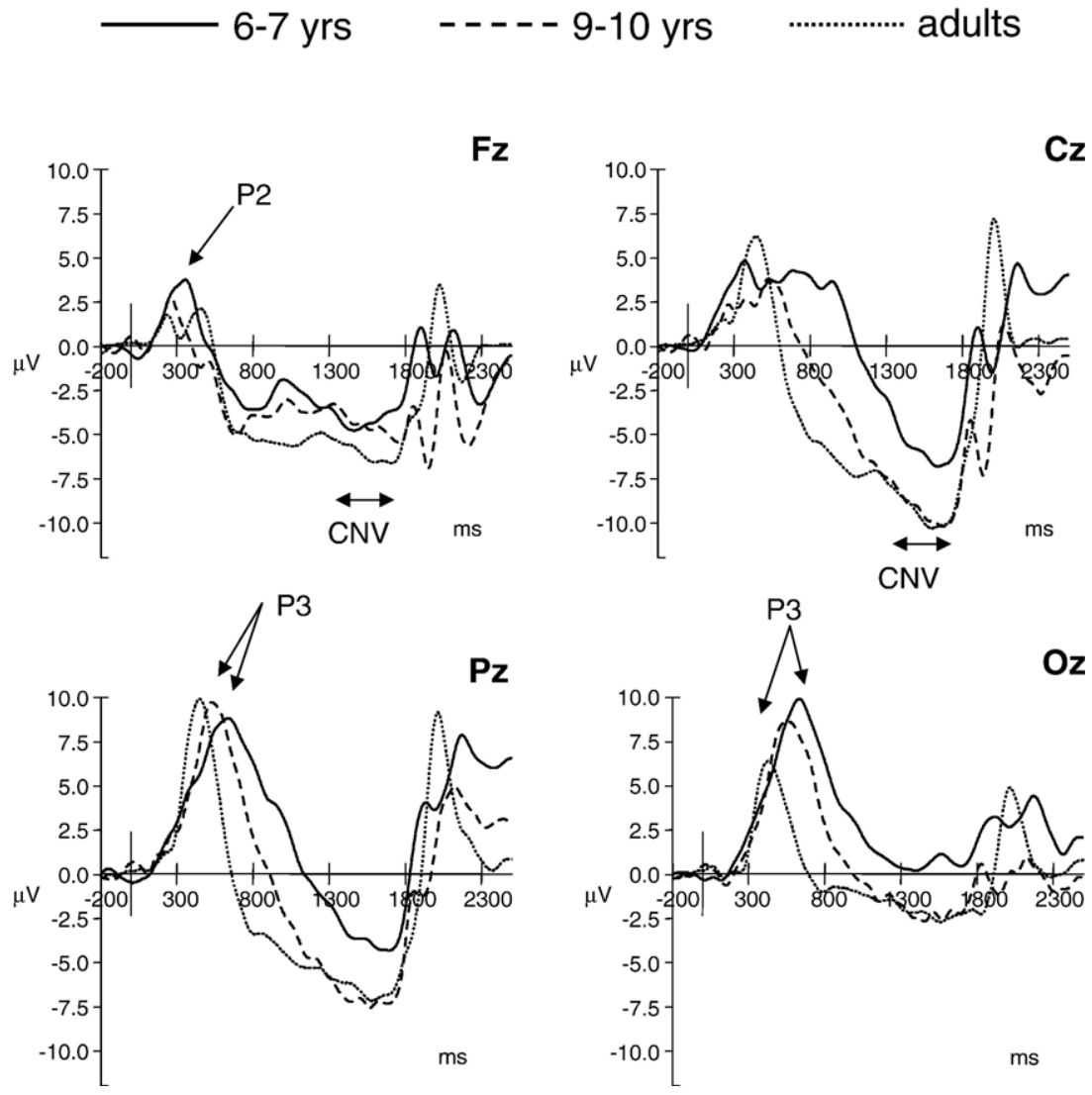

Fig. 2 - Grand average Cue-NoCue difference waves from children and adults at Fz, Cz, Pz and Oz leads. 
Table 3 - Mean area amplitudes in $\mu \mathrm{V}$ (standard deviations between brackets) in response to Cues and NoCues in all age groups for the P2 (Fz), P3 (Cz, Pz, Oz) and CNV (Fz, Cz, Pz and Oz)

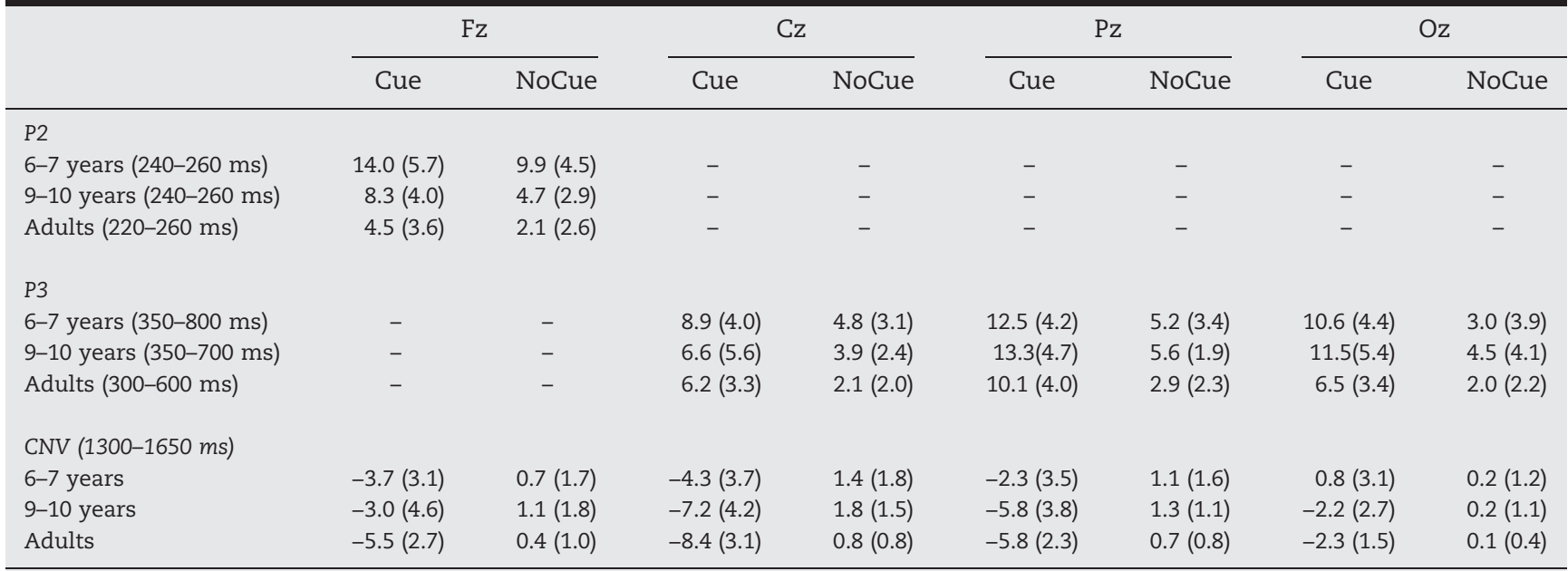

The windows in which P2 and P3 and CNV were scored are indicated in the first column.

temporal (T3, T4, T5, T6, TP7, TP8) electrodes. At all other leads, main Group effects occurred and were significant at $P<0.005$, except at Pz, P4, F8, FP2 and FT8 where significance level was $P<0.01$. The multivariate analysis to test for frontal-parietal differences yielded a significant Location $\times$ Group interaction $(F$ $(12,86)=3.50, P<0.0001)$. Further testing revealed no significant frontal-parietal differences in Nogo-P3 distribution between 910-year olds and adults as shown by the non-significant multivariate Location $\times$ Group: $F(6,27)=1.6, P=0.18$ interaction. Although Nogo-P3 activity was significantly smaller in 9-10year olds than adults at all frontal and parietal leads, both groups had similar distributions of activity. The frontalparietal distribution of younger children did differ from those of older children and adults (Location $\times$ Group: $F(6,26)=3.9$,
$P<0.007)$ and $F(6,26)=8.0, P<0.00001$, respectively). Next, amplitudes at the 6 fronto-central and centro-parietal leads were averaged to obtain one frontal and one parietal variable. Location effects did only occur between the youngest children and adults $(P<0.05)$, showing that the distribution had a more parietal dominance in young children due to enhanced frontocentral positivity in adults (see Fig. 3).

\section{Discussion}

The present study investigated the neurocognitive development of Cue-orientation, target-expectation and response preparation processes evoked by a warning stimulus and

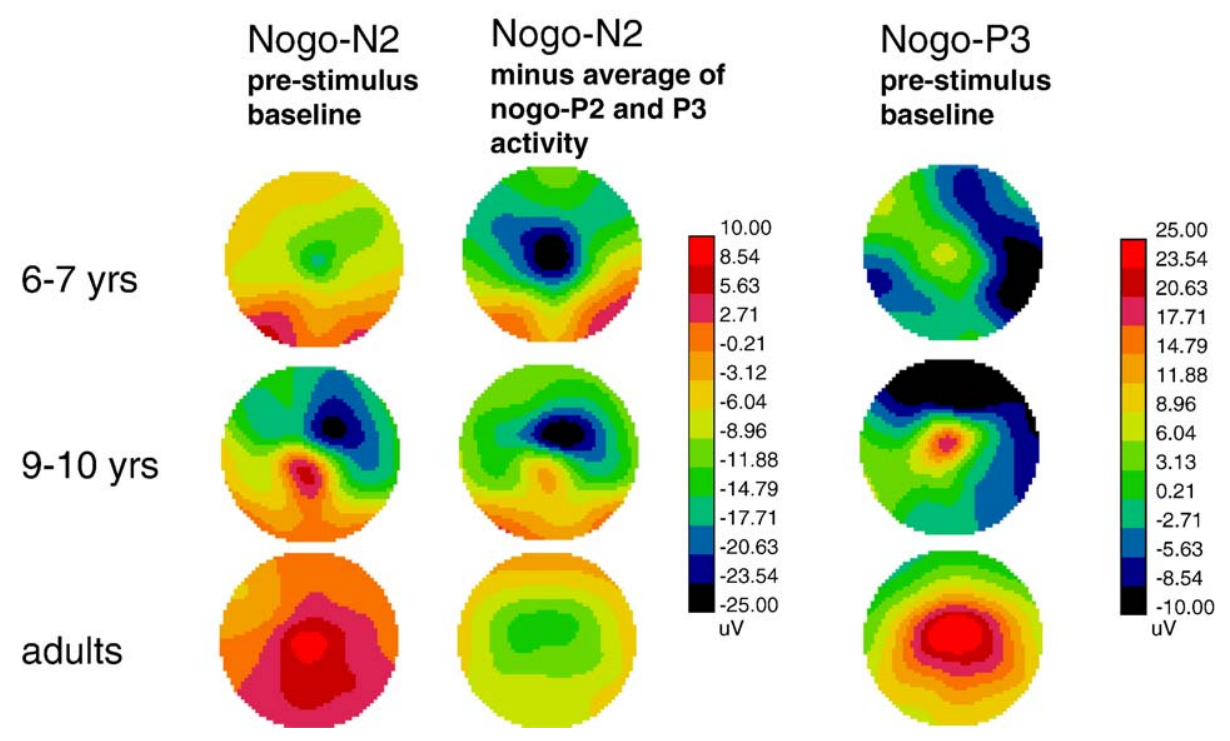

Fig. 3 - Voltage maps of Nogo-N2 and Nogo-P3 activity across 30 electrodes in the three age groups. The Nogo-N2 and Nogo-P3 maps are based on mean amplitudes in time segments in which amplitudes were maximal in the different groups (see Table 2). Furthermore, to exclude the influence of positivity surrounding the N2 on the scalp distribution, mean P2 and P3 activity was subtracted from the Nogo-N2 maps (for more elaborate description see methods section). Nogo-P3 maps were computed with reference to a $\mathbf{2 0 0} \mathrm{ms}$ prestimulus interval. 
subsequent conflict detection and response inhibition in a Go/ Nogo (CPT-AX) task from age 6 to adulthood with the aid of event-related brain potentials (ERPs).

The behavioral data revealed clear developmental patterns. Measures related to attention processing like percentage of correct detections and Inattention scores show largest developmental spurts between early (6-7 years) and late (910 years) childhood. Whereas there is still some prolonged development after age 10, the difference between older children and adults in attention-related behavioral measures is much smaller. In contrast, impulsive behavior (false alarms to Nogo stimuli and Impulsivity score) does not differ at all between 6-7 and 9-10-year-old children, but a significant reduction in impulsive behavior occurred after the age of 10 , even though the present task was a relatively simple task. This late development of response inhibition (reduction in impulsive behavior) is in agreement with other behavioral developmental studies and with protracted development of prefrontal lobe structures involved in the regulation of inhibitory control (Kanemura et al., 2003; Sowell et al., 1999; Luna and Sweeney, 2004). Event-related brain potential data, that will be discussed below, will give further insight into the neurobiological underpinnings of such behavioral development.

\subsection{Development of executive control processes; Nogo-N2 and $\mathrm{P} 3$ results}

As was discussed more elaborately in the Introduction, recently, in studies with adults, there has been debate about whether the Nogo-N2 and P3 components are both associated to the process of response inhibition. Whereas evidence in favor of an inhibition hypothesis for the Nogo-P3 is accumulating (Bruin et al., 2001; Bekker et al., 2004; Donkers and Van Boxtel, 2004), the Nogo-N2 amplitude seems to be a manifestation of the detection of conflict between the prepotent Goresponse and the inhibition of this response in regular $\mathrm{Go} /$ Nogo tasks (Donkers and Van Boxtel, 2004; Nieuwenhuis et al., 2003). In cued-Go/Nogo tasks or in tasks in which there is high Go probability, conflict might, however, also arise in the Nogo condition because Go-expectancy is violated (see Bekker et al., 2004). The present developmental results show a linear decrease in Go/Nogo-N2 effects from early childhood to young adulthood across midline frontal and fronto-central electrodes. Although all group contrasts were significant, differences in Go/Nogo-N2 effects between 6-7-year olds and both older children and adults were stronger than between the older children and adults. Regarding the fact that behavioral measures of inhibition control (e.g. false alarms in reaction to Nogo stimuli) showed the largest developmental progress only after the age of ten, these N2 findings seem more compatible with a conflict monitoring hypothesis than with an inhibition explanation. Since amplitude increases are commonly associated with higher attention allocation to a certain process, the amplitude decrease of the N2-effect with increasing age would in terms of a conflict hypothesis mean that the level of experienced conflict reduces with age. The present developmental pattern of Nogo-N2 effects is also in accordance with findings from two behavioral developmental studies (Ridderinkhof et al., 1997; Rueda et al., 2004a) investigating response conflict monitoring across several age groups in a flanker task.
Ridderinkhof et al. (1997) showed that conflict scores reached adult levels at the age of 10, whereas in Rueda et al. (2004a) scores appeared stable already after age 7 . Despite these differences, both studies showed that response conflict affected the performance of young children before or around the age of 7 most, and reached stability already in late childhood (from 10 years of age). Such early developmental stability in conflict performance but also in Nogo-N2 activity would not be expected in case of strong involvement of response inhibition. As mentioned earlier, motor inhibition behavior involves the recruitment of prefrontal cortex, that is known to undergo large maturational changes after late childhood, reaching maturity not until late adolescence (Bunge et al., 2002; Kanemura et al., 2003; Sowell et al., 1999). Finally, children with AttentionDeficit Hyperactivity Disorder, known to suffer from inhibition disorders, were reported to have reduced fronto-central NogoP3 activity, but similar or larger Nogo-N2 effects when compared to age-matched peers (Falgatter et al., 2004; Smith et al., 2004).

The topographic Nogo-N2 analysis shows that the Nogo distribution of all groups is dominated by a medial negativity that is largest at fronto-central electrodes, but diminishes gradually from young childhood through adulthood. Furthermore, the distributions of children show extra posterior positivity at bilateral temporal-parietal locations in 6-7-year olds and above medial parietal cortex in 9-10-year olds. Stronger posterior Nogo-N2 effects in children than adults were also reported by Ciesielski et al. (2004), but note that no significant frontal Go/Nogo-N2 effect was reported in children by these authors. Furthermore, in the latter study, the children group was composed of children within a rather broad age range from 6-12 years. Our results show that there are clear differences in the Nogo-N2 distribution between early and late childhood and this finding stresses the importance for future clinical and nonclinical developmental studies, to narrow the age-range for group inclusion. Conform our larger Nogo-N2 effects in 6-7 year old children across an array of fronto-parietal locations, several developmental fMRI studies (Bunge et al., 2002; Durston et al., 2002) also reported enhanced activation of prefrontal and posterior (parietal) areas in the Nogo-task in children relative to adults. The extra posterior activation in children might indicate that the Nogo condition requires more attentional processing or allocation during childhood. Such an explanation would be in line with the role that different parts of parietal cortex are known to play in the control and regulation of attention functions such as attention allocation and attention shifting in adults (Behrmann et al., 2004). But such an hypothesis can only be tested by performing source analysis. As argued before, the larger frontal Nogo-N2 effects early in development are probably a reflection of enhanced conflict monitoring. In adults, the Nogo-N2 component as well as the N2 evoked in response interference tasks has been repeatedly localized in the vicinity of Anterior Cingulate Cortex (ACC) (Bekker et al., 2005; Nieuwenhuis et al., 2003; Van Veen and Carter, 2002a,b), and caudal parts of ACC and pre-SMA regions have been particularly associated with conflict monitoring in fMRI studies (for review, see Botvinick et al., 2004; Fassbender et al., 2004). The Nogo-N2 scalp distributions of both children groups and adults suggest the involvement of a similar source in the vicinity of ACC that might be related to the process of 
conflict monitoring. Regarding the fact that anatomical ACC maturation is not fully completed in childhood (Cunningham et al., 2002), the extra posterior activation in children might be a compensation mechanism to maintain conflict monitoring performance at an acceptable level.

As opposed to the Nogo-N2, the Nogo-P3 effect showed a linear increase across age and supports an inhibition hypothesis for the Nogo-P3 (Bruin et al., 2001; Donkers and Van Boxtel, 2004). Whereas Nogo-P3 effects were absent in 6-7-year olds, a very small Nogo-P3 effect was present in late childhood, but only at the midline frontal-central electrodes. In adults, the Nogo-P3 effect was clearly present at a broader set of frontal and frontal-central electrodes. This late development of the Nogo-P3, starting at age 10, is in agreement with results reported in an earlier study from our lab (Jonkman et al., 2003) and a study by Okazaki et al. (2004), who also reported that the Nogo-P3 showed largest development after age 11. In the latter study, interstimulus intervals (ISIs) between warning stimuli and Go/Nogo stimuli were varied, suggesting that the longer intervals would make stronger demands on response inhibition. In line with this assumption, subjects made more false alarms to Nogo stimuli the longer the ISIs. Furthermore, and in line with an inhibition hypothesis for the Nogo-P3, after age 11, the Nogo-P3 showed stronger anteriorization with long ISI (3000 ms) than with short or medium (800 or $1500 \mathrm{~ms}$ ) ISI.

Whereas the Nogo-N2 component has been repeatedly localized in ACC in adults, the Nogo-P3 component has received less attention in source localization studies. In the one study known to us, in adults, the source generating Nogo-P3 was localized in left orbitofrontal cortex (Bokura et al., 2001). Orbitofrontal activation in the Nogo-condition was also reported in a developmental fMRI study by Casey et al. (1997). The Nogo-distribution of adults in the present study is, however, marked by a positivity above frontal and central electrodes, but with a clear maximum above the frontocentral midline electrode. This medial-frontal focus might be explained by a source in cingulate cortex; in an fMRI study, specific right lateralized cingulate cortex activation has been described to occur in a response inhibition condition and suggests functional specialization of subregions of ACC (Braver et al., 2001).

Concluding, whereas source localization studies including adult subjects suggest that conflict monitoring (as measured by Nogo-N2) relies on marked brain structures such as ACC, fMRI studies have shown that adequate response inhibition requires the activation of, and communication between a network of frontal-parietal areas (Garavan et al., 1999; Watanabe et al., 2002). The involvement of such a complicated network might explain why response inhibition does not reach maturity until late adolescence. Whereas the fundaments of such brain circuitry are in place by childhood, it undergoes further refinement by synaptic pruning and myelination from age 7 to 16 as indicated by increases in white matter especially in dorsal-frontal and parietal association areas (Sowell et al., 1999). Luna and Sweeney (2004) recently suggested that such structural changes during adolescence may have a direct effect on the efficiency of cognitive control by enhancing effective functional communication between posterior and anterior brain regions. Based on this literature and the present results, our hypothesis is that the inefficient inhibition performance seen during early and late childhood is caused by imperfect communication between parietal structures involved in processes such as attention allocation and stimulus evaluation and (pre)frontal areas controlling response inhibition. This hypothesis should be tested in future work.

\subsection{Development of Cue-orientation, Go-expectation and response preparation}

The present study also investigated neurodevelopmental changes in Cue-orientation, Go-expectation and response preparation processes evoked by cues that preceded Go/Nogo stimuli. The results showed that whereas both P2 and P3 amplitudes were larger in response to Cues than NoCues, developmental differences only occurred for the cue-P3. The P2 activity in CPT-AX tasks has been associated with early automatic sensory activation/orientation processes evoked by the cue-stimulus (Banaschewski et al., 2003). In Bekker et al. (2004), a similar enhancement of early positivity in response to Cues at the frontal lead was interpreted as Frontal Selection Positivity (FSP), reflecting early attentional selection. The absence of developmental differences in this early cue-positivity suggests that early cue-orientation or selection processes are fully matured in 6-7-year-old children. This might be due to relative early maturity of sensory areas involved in the generation of the P2 or FSP. In an earlier study from our lab, the FSP has been reported to be severely reduced in children with ADHD (Jonkman et al., 2004). The central-parietal (cue)-P3 has in adults been linked to Go-expectancy; the higher the Cue-P3 effect, the higher the expectation of the occurrence of a Go stimulus (Bekker et al., 2004; Van Leeuwen et al., 1998). Within this line of reasoning, the higher cue-P3 in children at occipital leads might indicate higher go expectancy in these groups. This enhanced expectancy might in turn cause higher conflict in Nogo conditions when the Go stimulus does not appear and might explain higher Nogo-N2 amplitudes in children. Bekker et al. (2004), studying response bias and inhibition in young adults in a similar CPT-AX task, recently also suggested links between target-expectancy (cue-P3 amplitudes) and subsequent Nogo-N2 effects since both were enhanced by an increase of Go probability from 50 to $75 \%$.

Even though target expectancy was higher in children, this did not result in stronger response preparation; late CNV amplitudes increased with age in a linear fashion. This delayed development of the CNV might be explained by immaturity of frontal-parietal networks that are involved in the regulation of motor behavior (response inhibition and preparation; Hester et al., 2004; Watanabe et al., 2002). When the reduced CNV activity in early childhood is interpreted as a sign of reduced response priming during the preparation interval, one can hypothesize that less response inhibition is required on the subsequent Nogo trial, explaining the absence of Nogo-P3 effects and supporting assumed links between inhibition and Nogo-P3. In adults, stronger prestimulus response priming has been reported to affect Nogo-P3 activity (Bruin et al., 2001). Accordingly, in the present study, adults show largest CNV amplitudes and largest Nogo-P3 effects. Thus, all together, the present data suggest a relation between the level of arousal or expectancy that is induced by cues (cue-P3) and the amount of experienced conflict at subsequent Nogo trials (Nogo-N2). In 
the same way, stronger response priming in the cue-target interval (as measured by CNV activity or Lateralized Readiness Potentials) is assumed to increase demands on response inhibition on Nogo trials visible as enhanced Nogo-P3 activity. The specificity of these effects needs further investigation by manipulating expectancy and response priming in a developmental study.

\subsection{Conclusions}

A linear decrease from young childhood to young adulthood was seen in ERP activity indicative of the level of Goexpectancy at occipital leads (cue-P3), whereas response preparation (CNV) activity linearly increased in amplitude with age. Furthermore, younger children had significantly larger frontal and posterior Nogo-N2 effects that were interpreted as signs of enhanced conflict monitoring/detection involving both parietal and frontal areas. It was argued that larger Go-expectancy in younger children might lead to enhanced conflict on subsequent Nogo-trials. The Nogo-N2 was followed by a significant Nogo-P3 effect across frontal-central electrodes in adults, but Nogo-P3 effects declined with deceasing age in a linear fashion. This decline in Nogo-P3, in combination with reduced CNV amplitudes in 6-7 year olds, was interpreted as being related to the late development of fronto-parietal networks involved in the regulation of motor preparation and response inhibition.

\section{Experimental procedure}

\subsection{Subjects}

Originally, 47 children participated in the study, afterwards 14 children ( 9 younger children and 5 older children) were excluded on the basis of scores in the clinical ( $t$ score $>63$ ) or subclinical threshold range (t scores between 60 and 63) on Internalizing (I), Externalizing (E) or Total Problem (T) subscales of the Child Behavior Checklist (CBCL; Achenbach, 1991). The CBCL is an instrument used for detection of behavioral problems and was filled in by the parents. Subjects with threshold scores were only excluded when these occurred on more than one subscale. For mean group $t$ scores on the different CBCL scales, see Table 4 . The remaining children were divided into two age groups; 16 children (4 boys and 12 girls) in the age range from $6-7$ years and 17 children ( 6 boys and 11 girls) in the age range of 9-10 years. Children were recruited from two different elementary schools and mean age was 7.1 years (SD $0.5)$ in the 6-7 years old group and 9.6 years $(\mathrm{SD}=0.6)$ in the 9-

Table 4 - Group means of $t$ scores on CBCL internalizing (I), externalizing (E) and total problem (T) subscales (SD between brackets) in children

\begin{tabular}{llll} 
& \multicolumn{1}{c}{ CBCL-I } & \multicolumn{1}{c}{ CBCL-E } & \multicolumn{1}{c}{ CBCL-T } \\
\hline 6-7 years & $48.9(7.1)$ & $47.0(9.6)$ & $46.1(9.9)$ \\
& range: 33-61 & range: $33-61$ & range: $26-59$ \\
9-10 years & $50.2(8.2)$ & $47.9(7.7)$ & $47.9(5.9)$ \\
& range: 32-62 & range: $32-61$ & range: $37-58$ \\
\hline
\end{tabular}

10 years old group. The adult group consisted of 17 students from Maastricht University (2 male and 15 female) aged between 19 and 23 years (mean age 21 years, SD $=1.7$ ) that were paid for participation. Children were rewarded with a present (a toy) after completion of the experiment.

To check for IQ subjects were administered the Raven IQ test (Raven et al., 1983). In the young group, IQ scores of five children are missing due to an administration error but there were no indications of academic problems in these children as indicated by CBCL. Of the remaining $116-7$-year-old children, all but one scored above the 50th percentile of the norm population $(M=75$ th percentile, $S D=22$, range $25-95$ th percentile). From the 9-10-year-old children all but one child scored above the 50th percentile of the norm population $(\mathrm{M}=80$ th percentile, $\mathrm{SD}=21$, range $25-95$ th percentile). Adults all scored above the 90th percentile. Whereas IQ did not significantly differ between the child groups $(P=0.44)$, adults had somewhat higher IQ. To exclude the possibility that differences in IQ explained task performance differences between the age groups, first a correlation analysis was performed to check whether IQ score was related to behavioral parameters. If so, for the concerned variables, a covariance analysis was performed including IQ and it was checked whether this changed the significance of Group effects (see Results). The present study was approved by a local Ethical Committee and is performed in accordance with the ethical standards laid down in the 1964 Declaration of Helsinki. The caretakers of all children filled in an informed consent form prior to the start of the study.

\subsection{Procedure}

For a description of the experimental procedure, the reader is referred to a previous paper by Jonkman et al. (2003).

\subsection{CPT-AX task}

The CPT-AX task consisted of a sequence of 11 different letters (A, B, C, D, E, F, G, H, J, L and X). The letters were white and were presented one by one between two vertical bars at the center of the screen on a black background. The vertical bars and the letters had a height of $2 \mathrm{~cm}$ and letters had a width of $1.5 \mathrm{~cm}$. Subjects were seated approximately $50 \mathrm{~cm}$ in front of a $17^{\prime \prime}$ VGA monitor.

The task instruction to the subjects was to press a button with their right hand when the letter $\mathrm{X}$ appeared, but only when it was preceded by the A (A-X sequence, Go condition). When an $\mathrm{A}$ is followed by another letter, the prepared response had to be inhibited (A-not-X, Nogo condition). The task was administered in four separate blocks of 124 trials each, consisting of $24 \times$ and 24 A stimuli (of which 12 As and $12 \mathrm{Xs}$ were part of the A-X (Go) sequence, 12 As were part of A-not-X (Nogo) sequences and $12 \mathrm{Xs}$ were presented alone, without a preceding A). Thus, the occurrence of Go and Nogo trials was equiprobable (in $10 \%$ of all presentations), since As were presented in both Go and Nogo sequences and Xs were presented in Go sequences and alone, total probability of As and Xs was comparable (20\%). The remaining 76 trials consisted of 6 trials of letters B, C, D, E, F, G, J, L (total 48 trials) and 28 presentations of the letter $\mathrm{H}$. The letter $\mathrm{H}$ was presented more often to keep 
the probability (23\%) comparable to that of the letters A and X. A total trial lasted $1650 \mathrm{~ms}$, with a stimulus duration of $150 \mathrm{~ms}$ and a fixed interstimulus-interval (ISI) of $1500 \mathrm{~ms}$. Before the start of the experimental session, the task was practiced (each subject received 25 practice trials) and all subjects scored at or above $80 \%$ correct responses and had less than $10 \%$ false alarms during the practice session.

\subsection{Electrophysiological recording}

For measurement of the EEG, an electro-cap consisting of 30 tin electrodes [Fp1, Fp2, F7, F3, Fz, F4, F8, FT7, FC3, FCz, FC4, FT8, T7, C3, Cz, C4, T8, TP7, CP3, CPz, CP4, TP8, T5, P3, Pz, P4, T6, O1, $\mathrm{Oz}, \mathrm{O} 2$; nomenclature according to American Electroencephalographic Society (1991)] was used. All electrodes were referenced to the left mastoid, one of the electrodes in the electro-cap (FPz) was used as ground. The vertical EOG was recorded from infra-orbital and supraorbital tin electrodes placed in line with the pupil of the left eye; for measurement of the horizontal EOG, two tin electrodes were attached to the outer canthi of both eyes. All electrode impedances were kept below $5 \mathrm{k} \Omega$, with exception of EOG electrodes in children that were held below $18 \mathrm{k} \Omega$.

\subsection{Data analysis}

\subsubsection{Behavioral measures}

Besides the percentage of correct Go responses, mean reaction times (RT), variability of reaction times (SDRT) and percentage of false alarms, impulsivity and inattention scores were computed according to Halperin et al. (1988); Overtoom et al. (1998). The impulsivity score was calculated as the sum of fast A-not-X errors (defined as a response to the letter following the A with an RT faster than the mean hit RT of a subject in the task) and slow A-only errors (premature responses to the $\mathrm{A}$ with RTs longer than $1250 \mathrm{~ms}$ ) divided by the total number of A-X (Go) and A-not-X (Nogo) trials (144 trials). The inattention score was computed as the sum of the total number of misses (no response to Go trial) and number of slow X-only errors (response to X not preceded by A with an RT higher than the mean hit RT of the subject in the task) divided by the total number of Go and X-only trials (96 trials).

\subsubsection{EEG and ERP data}

The continuous EEG was divided into 496 epochs of $1850 \mathrm{~ms}$, from $200 \mathrm{~ms}$ prestimulus to $1650 \mathrm{~ms}$ poststimulus, all epochs were aligned to a baseline from - 200 to $0 \mathrm{~ms}$ preceding the stimulus. Epochs containing artifacts or horizontal eye movements exceeding $\pm 100 \mu \mathrm{V}$ were rejected from the database, for four of the youngest subjects, this criterion was increased to $\pm 120 \mu \mathrm{V}$. Vertical EOG artifacts were removed from the data by applying an eye-movement correction algorithm (Semlitsch et al., 1986). Next, average ERPs were computed separately for each subject in four different stimulus conditions: (1) Go trials (ERP to Xs preceded by A), (2) Nogo trials (ERPs to not-X letters following A), (3) Cue trials (ERPs to letters A summed over A-X and A-not-X categories) and (4) NoCue trials in which single letters were presented (B, C, D, E, F, G, J, L) that did not precede or follow an $\mathrm{A}$ or $\mathrm{X}$. In the averaging procedure, only trials with correct responses (Go) or correctly rejected trials (Nogo, Cue and NoCue) were included. The maximum amount of trials in Go and Nogo conditions was 48. In the 6-7-year olds, the amount of artifact-free EEG epochs contained in the singlesubject averages ranged from 14-46 trials (group mean $=32$ trials, $\mathrm{SD}=10$ ) in the Go condition and 20-46 trials in the Nogo condition (group mean 36 trials, SD = 9). In the 9-10-year olds, included trials ranged from 26-47 (mean 38 trials, $S D=6$ ) in Go condition and from 27-47 (mean 40 trials, SD = 5) in the Nogo condition. In the adult group, all subjects had more than 35 trials in both averages. In the Cue and NoCue conditions, all single-subject averages contained more than 30 trials; the maximum number of A and other letter trials was respectively 96 trials and 208 trials.

For the Nogo-N2 and P3 ERP analyses, mean area amplitudes at 30 leads were computed in 20-ms time segments running from 120-500 ms. Cue-P2 and Cue P3 analyses were performed by computing mean amplitudes in Cue and NoCue ERPs in 20-ms segments within a time window from 120-500 ms for P2 and from $250850 \mathrm{~ms}$ for P3. For the CNV, mean area amplitude was determined in one broader window from 1300$1650 \mathrm{~ms}$ in all subjects. Because of latency differences between age groups, it was first determined on the basis of group means at the relevant leads in which time segments, the different ERP components were maximal (see Results). Next, mean amplitudes in the relevant windows and at relevant leads (see Statistical analysis) were entered in statistical analyses.

For the topographical analyses of the Nogo-N2, at 30 leads, we computed Nogo-N2 amplitudes that were corrected for the possible influence of surrounding positive activity on which the $\mathrm{N} 2$ rides (see Bekker et al., 2005). This was done by first selecting the 20-ms time segments in which positive activity preceding (P2) and following (P3) the N2 was maximal in each of the groups on the basis of group means. Then, for all subjects, the mean amplitudes in these P2 and P3 windows were averaged and subtracted from the Nogo-N2 activity. The topographical analyses were performed on these corrected Nogo-N2 values. The topographical analysis of the Nogo-P3 included "non-corrected" amplitudes that were computed relative to the $200 \mathrm{~ms}$ prestimulus baseline as was the case in the ERP analysis.

\subsection{Statistical analysis}

\subsubsection{Behavioral measures}

For all behavioral measures, group effects were tested by oneway ANOVAs with a between factor Group (6-7 years, 910 years and adults). Measures were: reaction time to correct Go responses (Go-RT), variability Go-RT (standard deviation of $\mathrm{RT}$ ), percentage of correct Go responses (hits), percentage of false alarms to A-not-X (Nogo) stimuli and Impulsivity and Inattention scores (see Data analysis). When ANOVA Group contrasts were significant, further differences between groups were tested by performing independent-samples $t$ tests. Equality of variances was tested with Levene's test and, if necessary, corrections for unequality were performed and accompanying $t$ and $P$ values reported. Two-tailed significance levels of $5 \%$ were adopted.

\subsubsection{ERP measures}

To test whether there are developmental differences in Cueorientation, Go-expectation, response preparation (Cue/ 
NoCue comparison) and conflict monitoring and response inhibition (Go/Nogo comparison), repeated measures analyses of variance were performed for Cue-P2, Cue-P3, CNV, Nogo-N2 and Nogo-P3 respectively at the leads where the different waves are known to be most prominent (based on the literature).

The Nogo-N2 and P3 analysis included the two within factors Leads (Fz and FCz) and Condition (Go versus Nogo) and a between factor Group (6-7 and 9-10-year-old children and adults). The Cue-P2 analysis included a within factor Condition (Cue/NoCue) and a between factor Group (3 levels) and was performed at the Fz electrode. Cue-P3 and CNV analysis also involved the factors Condition (Cue/NoCue) and Group (3 levels) but included an extra within factor Leads with 3 levels (Cz, Pz and $\mathrm{Oz}$ ) for Cue-P3 and 4 levels (Fz, Cz, Pz and Oz) for $\mathrm{CNV}$. Significant interactions involving the Group factor were further tested by performing post hoc tests, comparing the three groups. For all analyses, a two-tailed significance level of $P<0.05$ was adopted.

Differences in the scalp distribution of Nogo-N2 and NogoP3 between the two groups of children and adults were investigated by first running a multivariate analyses including 30 leads and a between factor Group to get a first indication of the locations at which Group differences occurred. Next, to study Frontal-Parietal differences between the three age groups, a multivariate repeated measures analysis of variance (including the leads F3, Fz, F4, FC3, FCz, FC4 and CP3, CPz, CP4, $\mathrm{P} 3, \mathrm{Pz}, \mathrm{P} 4)$ was executed containing the within factors Location (Frontal, Parietal) and Hemisphere (left, midline and right) and a between factor Group (3). These analyses made use of mean Nogo-N2 and P3 amplitudes in time windows that were similar to those used in the ERP analyses (see Table 2), but Nogo-N2 distributions were corrected for P2 and P3 activity preceding and following the N2. For these analyses, a twotailed significance level of $P<0.05$ was adopted.

\section{Acknowledgments}

The author thanks Dr. J.E.A. Stauder, M. Lansbergen and M. Groen for help in recruitment and testing of the subjects for this study. Furthermore, thanks go to two anonymous reviewers for their valuable suggestions to improve the paper.

\section{R E F E R E N C ES}

Achenbach, T.M., 1991. Manual for the Child Behavior Checklist/4-18. University of Vermont, Department of Psychiatry, Burlington, VT.

American Electroencephalographic Society, 1991. American electrencephalographic society guidelines for standard electrode position nomenclature. J. Clin. Neurophysiol. 8, 200-202.

Banaschewski, T., Brandeis, D., Heinrich, H., Albrecht, B., Brunner, E., Rothenberger, A., 2003. Association of ADHD and conduct disorder, brain electrical evidence for the existence of a distinct subtype. J. Child Adolesc. Psychiatry 44, 356-376.

Behrmann, M., Geng, J.J., Shomstein, S., 2004. Parietal cortex and attention. Curr. Opin. Neurobiol. 14, 212-217.

Bekker, E.M., Kenemans, J.L., Verbaten, M.N., 2004.
Electrophysiological correlates of attention, inhibition, sensitivity and bias in a continuous performance task. Clin. Neurophysiol. 115, 2001-2013.

Bekker, E.M., Kenemans, J.L., Verbaten, M.N., 2005. Source analysis of the N2 in a cued Go/NoGo task. Brain Res. Cogn. Brain Res. 22, 221-231.

Bokura, H., Yamaguchi, S., Kobayashi, S., 2001. Electrophysiological correlates for response inhibition in a Go/NoGo task. Clin. Neurophysiol. 112, 2224-2232.

Botvinick, M.W., Cohen, J.D., Carter, C.S., 2004. Conflict monitoring and anterior cingulate cortex: an update. Trends Cogn. Sci. 8, 539-546.

Braver, T.S., Barch, D.M., Gray, J.R., Molfese, D.L., Snyder, A., 2001. Anterior cingulate cortex and response conflict: effects of frequency, inhibition and errors. Cereb. Cortex. 11, 825-836.

Bruin, K.J., Wijers, A.A., 2002. Inhibition, response mode, and stimulus probability: a comparative event-related potential study. Clin. Neurophysiol. 113, 1172-1182.

Bruin, K.J., Wijers, A.A., van Staveren, A.S.J., 2001. Response priming in a Go/Nogo task: do we have to explain the Go/Nogo N2 effect in terms of response activation instead of inhibition? Clin. Neurophysiol. 112, 1660-1671.

Bunge, S.A., Dudukovic, N.M., Thomason, M.E., Vaidya, C.J., Gabrieli, D.E., 2002. Immature frontal lobe contributions to cognitive control in children: evidence from fMRI. Neuron 33, 301-311.

Casey, B.J., Trainor, R.J., Orendi, J.L., Schubert, A.B., Nystrom, L.E., Giedd, J.N., Castellanos, F.X., Haxby, J.V., Noll, D.C., Cohen, J.D., Forman, S.D., Dahl, R.E., Rapoport, J.L., 1997. A developmental functional MRI study of prefrontal activation during performance of a Go-No-Go task. J. Cogn. Neurosci. 9, 835-847.

Ciesielski, K.T., Harris, R.J., Cofer, L.F., 2004. Posterior brain ERP patterns related to the Go/No-Go task in children. Psychophysiology 41, 882-892.

Cunningham, M.G., Bhattacharyya, S., Benes, F.M., 2002. Amygdalo-cortical sprouting continues into early adulthood: implications for the development of normal and abnormal function during adolescence. J. Comp. Neurol. 453, 116-130.

Davis, E.P., Bruce, J., Snyder, K., Nelson, C.A., 2003. The X-trials: neural correlates of an inhibitory control task in children and adults. J. Cogn. Neurosci. 15, 432-443.

Donkers, F.C., Van Boxtel, G.J., 2004. The N2 in go/no-go tasks reflects conflict monitoring not response inhibition. Brain Cogn. 56, 165-176.

Durston, S., Thomas, K.M., Yang, Y., Ulug, A.M., Zimmerman, R.J., Casey, B.J., 2002. A neural basis for the development of inhibitory control. Dev. Sci. 5, 9-16.

Fallgatter, A.J., Brandeis, D., Strik, W.K., 1997. A robust assessment of the Nogo-anteriorisation of P300 microstates in a cued continuous performance test. Brain Topogr. 9, 295-302.

Falgatter, A.J., Ehlis, A.C., Seifert, J., Strik, W.K., Scheuerplug, P., Zilessen, K.E., Herrmann, M.J., Warnke, A., 2004. Altered response control and anterior cingulate function in attention-deficit/hyperactivity disorder boys. Clin. Neurophysiol. 115, 973-981.

Fassbender, C., Murphy, K., Foxe, J.J., Wylie, G.R., Javitt, D.C., Robertson, I.H., Garavan, H., 2004. A topography of executive functions and their interactions revealed by functional magnetic resonance imaging. Brain Research Cogn. Brain Res. 20, 132-143.

Garavan, H., Ross, T.J., Stein, E.A., 1999. Right hemisphere dominance of inhibitory control: an event-related functional MRI study. Proc. Natl. Acad. Sci. U. S. A. 96, 8301-8306.

Halperin, J.M., Wolf, L.E., Pascualvaca, D.M., Newcorn, J.H., Healey, J.M., O’Brien, J.D., Morgenstein, A., Young, J.G., 1988. Differential assessment of attention and impulsivity in children. J. Am. Acad. Child Adolesc. Psych. 27, 326-329.

Hester, R.L., Murphy, K., Foze, J.J., Foxe, D.M., Javitt, D.C., Garavan, 
H., 2004. Predicting success: patterns of cortical activation and deactivation prior to response inhibition. J. Cogn. Neurosci. 6, 776-785.

Jodo, E., Kayama, Y., 1992. Relation of a negative component to response inhibition in a Go/No-Go task. Electroencephalogr. Clin. Neurophysiol. 82, 477-482.

Johnstone, S.J., Pleffer, C.B., Barry, R.J., Clarke, A.R., Smith, J.L., 2005. Development of inhibitory processing during the Go/ Nogo task. A behavioural and event-related potential study of children and adults. J. Psychophysiol. 19, 11-23.

Jonkman, L.M., Lansbergen, M., Stauder, J.E.A., 2003. Developmental differences in behavioral and event-related brain responses associated with response preparation and inhibition in a go/nogo task. Psychophysiology 40, 752-761.

Jonkman, L.M., Kenemans, J.L., Kemner, C., Verbaten, M.N., van Engeland, H., 2004. Dipole source localisation of event-related brain activity indicative of an early visual selective attention deficit in ADHD children. Clin. Neurophysiol. 115, 1537-1549.

Kanemura, H., Aihara, M., Aoki, S., Araki, T., Nakazawa, S., 2003. Development of the prefrontal lobe in infants and children: a three-dimensional magnetic resonance volumetric study. Brain Dev. 25, 195-199.

Kok, A., 1986. Effects of degradation of visual stimuli on components of the event-related potential (ERP) in Go/Nogo reaction tasks. Biol. Psychol. 23, 21-38.

Luna, B., Sweeney, J.A., 2004. The emergence of collaborative brain function: fMRI studies of the development of response inhibition. Ann. N. Y. Acad. Sci. 1021, 296-309.

McCallum, W.C., 1988. Potentials related to expectancy, preparation and motor activity. In: Picton, T.W. (Ed.), Handbook of Electroencephalography and Clinical Neurophysiology: Human Event-Related Potentials, Revised Series, vol. 3. Elsevier, New York, pp. 427-534.

Nieuwenhuis, S., Yeung, N., van den Wildenberg, W., Ridderinkhof, K.R., 2003. Eeletrophysiological correlates of anterior function in a go/no-go task: effects of response conflict and trial type frequency. Cogn. Affect. Behav. Neurosci. 3, $17-26$.

Okazaki, S., Hosokawa, M., Kawakubo, Y., Ozaki, H., Maekawa, H., Futakami, S., 2004. Developmental change of neurocognitive motor behaviour in a continuous performance test with different interstimulus intervals. Clin. Neurophysiol. 115, 1102-1113.

Overtoom, C.C., Verbaten, M.N., Kemner, C., van Engeland, H., Buitelaar, J.K., Camfferman, G., Koelega, H.S., 1998. Associations between event-related potentials and measures of attention and inhibition on the continuous performance task in children with ADHD and normal controls. J. Am. Acad. Child Adolesc. Psych. 37, 977-985.

Ramautar, J.R., Kok, A., Ridderinkhof, K.R., 2004. Effects of stop-signal probability in the stop-signal paradigm: the N2/P3 complex further validated. Brain Cogn. 56, 234-252.

Raven, J.C., Court, F.C., Raven, J., 1983. Manual for Raven's progressive matrices and vocabulary scales. H.K. Lewis \& Co. Ltd., London.

Ridderinkhof, K.R., van der Molen, M.W., Band, G.P.H., Bashore, T.R., 1997. Sources of interference from irrelevant information: a developmental study. J. Exp. Child Psychol. 65, 315-341.

Ridderinkhof, K.R., Ullsperger, M., Crone, E.A., Nieuwenhuis, S., 2004. The role of the medial frontal cortex in cognitive control. Science 15, 443-447.

Rohrbaugh, J.W., Gaillard, A.W.K., 1983. Sensory and motor aspects of the contingent negative variation. In: Gaillard, A.W.K., Ritter, W. (Eds.), Tutorials in Event-Related Potential Research: Endogenous Components. North Holland, Amsterdam, pp. 269-310.

Rueda, M.R., Fan, J., McCandliss, B.D., Halparin, J.D., Gruber, D.B., Lercari, L.P., Posner, M.I., 2004a. Development of attentional networks in childhood. Neuropsychologia 42, 1029-1040.

Rueda, M.R., Posner, M.I., Rothbart, M.K., Davis-Stober, C.P, 2004b. Development of the time course for processing conflict: an event-related potentials study with 4 year olds and adults. BMC Neurosci. 5, 39.

Segalowitz, S.J., Davies, P.L., 2004. Charting the maturation of the frontal lobe: an electrophysiological strategy. Brain Cogn. 55, 116-133.

Segalowitz, S.J., Unsal, A., Dywan, J., 1992. Cleverness and wisdom in 12-years-olds: electrophysiological evidence for late maturation of the frontal lobe. Dev. Neuropsychol. 8, 279-298.

Semlitsch, H.V., Anderer, P., Schuster, P., Presslich, O., 1986. A solution for reliable and valid reduction of ocular artefacts, applied to the P300 ERP. Psychophysiology 23, 695-703.

Smith, J.L., Johnstone, S.J., Barry, R.J., 2004. Inhibitory processing during the Go/Nogo task: an ERP analysis of children with attention-deficit/hyperactivity disorder. Clin. Neurophysiol. 115, 1320-1331.

Sowell, E.R., Thompson, P.M., Holmes, C.J., Batth, R., Jernigan, T.L., Toga, A.W., 1999. Localizing age-related changes in brain structure between childhood and adolescence using statistical parametric mapping. NeuroImage 9, 587-592.

Van Leeuwen, T.H., Steinhausen, H.C., Overtoom, C.C., PascialMarqui, R.D., van 't-Klooster, B., Rothenberger, A., Sergeant, J.A., Brandeis, D., 1998. The continuous performance test revisited with neuroelectric mapping: impaired orienting in children with attention deficits. Behav. Brain Res. 94, 97-110.

Van 't Ent, D., Apkarian, P., 1999. Motoric response inhibition in finger movement and saccadic eye movement: a comparative study. Clin. Neurophysiol. 110, 1058-1072.

Van Veen, V., Carter, C.S., 2002a. The anterior cingulate as a conflict monitor: fMRI and ERP studies. Physiol. Behav. 77, 477-482.

Van Veen, V., Carter, C.S., 2002b. The timing of action-monitoring processes in the anterior cingulate cortex. J. Cogn. Neurosci. 14, 593-602.

Watanabe, J., Sugiura, .M., Sato, K., Sato, Y., Maeda, Y., Matsue, Y., Fukuda, H., Kawashima, R., 2002. The human prefrontal and parietal association cortices are involved in No-Go performances: an event-related fMRI study. NeuroImage 17, 1207-1216.

Williams, B.R., Ponesse, J.S., Schachar, R., Logan, G.D., Tannock, R., 1999. Development of inhibitory control across the lifespan. Dev. Psychol. 35, 205-213. 